\title{
CFD ANALYSIS OF HEAT EXCHANGER MODELS DESIGN USING ANSYS FLUENT
}

\author{
Ram Kishan \\ M. Tech., Student, Department of Mechanical Engineering, \\ Sachdeva Institute of Technology, Farah, Mathura, India \\ Devendra Singh \\ Assistant Professor, Department of Mechanical Engineering, \\ Sachdeva Institute of Technology, Farah, Mathura, India \\ Ajay Kumar Sharma* \\ Assistant Professor, Department of Mechanical Engineering, \\ Institute of Engineering and Technology Lucknow, India \\ *Corresponding Author
}

\begin{abstract}
The aim of the study is design tube and box heat exchanger with various pattern of tubes and examine the flow and temperature field at inlet and outlet point of tube and container using ANSYS programming tool. Three types of heat exchangers are planned in this examination with various structures of cylinders contains of $175 \mathrm{~mm}$ breadth and $1000 \mathrm{~mm}$ length shell measurement $175 \mathrm{~mm}$. To expand the rate of heat exchange of heat exchanger advancement is done which tries to distinguish the best parameter combination of heat exchangers. The prefix parameter (tube width) is utilized as an info variable and the yield parameter is the most extreme temperature distinction of container and tube heat exchanger. Three types models are design on the basis tubes varieties of heat exchanger and CFX examination is completed in ANSYS 14.0.
\end{abstract}

Keywords: Shell and tube heat exchanger, Ansys, Temperature, Heat transfer coefficient, thermal analysis, FEM.

Cite this Article: Ram Kishan, Devendra Singh and Ajay Kumar Sharma, CFD Analysis of Heat Exchanger Models Design Using Ansys Fluent. International Journal of Mechanical Engineering and Technology 11(2), 2020, pp. 1-9.

https://iaeme.com/Home/issue/IJMET?Volume $=11 \&$ Issue $=2$

\section{INTRODUCTION}

The sole purpose of the heat exchangers is to enhance the heat transfer between the two fluids. This reduces the energy requirements and helps make the process more efficient. It has been widely admired that the counter flow heat exchanger has a greater heat transfer capability as 
compare to other heat exchangers. In counter flow heat exchanger the fluid flows inside the tube and kept apart from each other with a boundary wall where the heat transfers from one fluid to other without mingling. It has great advantage of very compact in size. Heat exchanger is designed and modeled using the correlation based analytical approach which means constantly used to improve the data periodically. Correlation approach is also applied for the sizing and used for getting better results after successive iteration. Although it is very difficult to get the right combination for the analysis, the CFD makes it easier for the calculation. The transfer of sensible heat takes place due to the significances of second law of thermodynamics. Different computational analysis has been adopted to analyze and configure the heat exchanger with some altercation like changing the inlet temperatures and mass flow rates etc. The CFD defines the significance of inlet flow rates to analyze the effectiveness of heat exchanger. Higher temperature difference and mass flow rates makes the counter flow heat exchanger pre-eminent among other heat exchanger. Heat exchangers are one of the mostly used equipment in the process industries. A heat exchanger is a device in which two liquid streams, one hot and one cold, are carried into thermal contact with each other in order to exchange transfer heat from the hot liquid stream to the cool one. It gives a moderately large surface area of heat exchange for given volume of the equipment. heat exchangers might be characterized based on contacting methods, development, flow arrangement plan or surface compactness. A shell and tube heat transfer devices are largely demanded in process plants. heat exchangers are one of the generally utilized in the process plant. heat transfer devices are utilized to exchange heat between two types of fluid. One can understand their use that any procedure which include chilling, heating, condensation, boiling or evaporation will need a heat transfer device for that type of work. Process liquids, typically are warmed or cooled before the procedure or experience a stage change. Several heat exchangers are named by their application. For example, heat transfer devices being utilized to condense is called as condensers, also heat exchanger for boiling purpose are called boilers. performance and strength of heat exchangers are studied through the measure of heat transfer utilizing minimum territory of heat exchange and weight drop. Weight drop and region required for a specific measure of heat exchange, gives knowledge about the capital expense and power necessities of a heat exchanger.

\section{FLOW ARRANGEMENT}

There are two essential groupings of heat exchangers as per their stream course of action. In parallel-stream exchangers, the two liquids goes in the exchanger at a parallel end, and moves in parallel to each other to the opposite side. In counter-stream heat exchangers the liquids enter the exchanger from inverse closures. The counter flow plan is most effective, in that it can exchange the most heat from the heat medium. See countercurrent trade. In a cross-stream heat exchanger, the liquids make a trip generally opposite to each other through the exchanger. For effectiveness, warm exchangers are intended to augment the surface territory of the divider between the two liquids, while limiting protection from liquid course through the exchanger. The exchanger's execution can likewise be influenced by the expansion of blades or creases in one or the two bearings, which increment surface territory and may channel liquid stream or incite disturbance. 


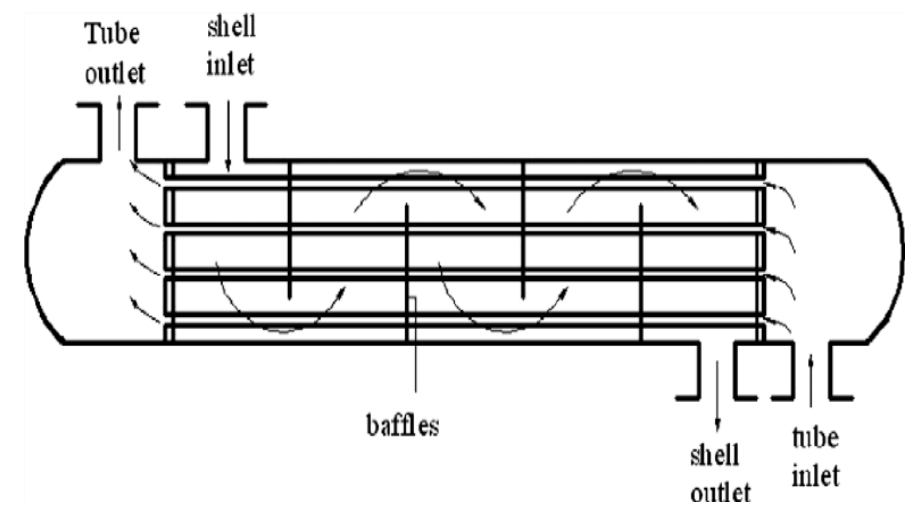

Figure 1: Shell and Tube Heat Exchanger with one shell pass and one tube pass

The main temperature over the heat exchange surface shifts with position, however a proper means temperature can be characterized. In most basic frameworks this is the "log mean temperature difference" (LMTD). In some cases, coordinate information of the LMTD isn't accessible and the NTU strategy is utilized.

\section{DESIGN OF HEAT EXCHANGER IN ANSYS}

To execute the finite element investigation of the heat exchanger models whilst heat exchanger tubes arrangement enhances the temperature and the heat transfer to the water with the help of tubes, a structural examination performed with the use of ANSYS Workbench V.14.0. At this step the research of the heat exchanger models is a steady state thermal analysis one, while minor modification in heat exchanger models material used aluminum alloy and copper. The model of the heat exchanger models is designed in ANSYS Workbench.

Table 1: Dimensions and material of Solar water heater models

\begin{tabular}{|l|l|l|l|}
\hline $\begin{array}{l}\text { Dimensions } \\
\text { of Tubes }\end{array}$ & $\begin{array}{l}\text { Dimensions of } \\
\text { Shell Body }\end{array}$ & \multicolumn{1}{|c|}{ Materials Detail } & Types of Tube Pattern \\
\hline $\begin{array}{l}\text { Outer } \\
\text { Diameter }= \\
25 \mathrm{~mm}\end{array}$ & $\begin{array}{l}\text { Length }=1000 \\
\mathrm{~mm}\end{array}$ & Tubes Material = Copper & Straight Parallel Tube \\
\hline $\begin{array}{l}\text { Inner } \\
\text { diameter }= \\
22 \mathrm{~mm}\end{array}$ & $\begin{array}{l}\text { Width }=175 \\
\mathrm{~mm}\end{array}$ & $\begin{array}{l}\text { Shell Material }= \\
\text { Aluminum Alloy }\end{array}$ & 'S' pattern Tube \\
\hline & $\begin{array}{l}\mathrm{Height}=175 \\
\mathrm{~mm}\end{array}$ & Zigzag Pattern Tube \\
\hline \multicolumn{2}{|l|}{ Fluid used $=$ water } \\
\hline \multicolumn{2}{|l|}{ Inlet Temperature of Cold water $=12^{\circ} \mathrm{C}$} \\
\hline \multicolumn{2}{|l|}{ Mass flow ratere of $=0.05 \mathrm{Kg} / \mathrm{Sec}$ at Inlet } \\
\hline
\end{tabular}

\section{METHODOLOGY}

As per study it is found that CFD examination includes mainly three types of steps are described:

Pre-Processing: This is the beginning stage of the CFD simulation process, which helps to properly explain the geometry. The selected stream domain is divided into a number of smaller components. CFD-GEOM, ANSYS, Meshing, ANSYS, ICEM CFD, T Grid etc. are distinguished pre-processing programming. Pre-preparation includes the problem, the creation 
of a 3D display, the Ansys workbench, meshing and physical working conditions called limits.

Solving or Processing: If fluid characteristics, stream physical science have been studied, then the conditions for handling them with PCs are limited. Extraordinary business programming for this purpose is available: CFD++, Open FOAM, ANSYS CFX, Star CCM, ANSYS FLUENT etc. Using this item, the management requirements for stream science can be understood. Handling involves unwinding numerical or logical fluid stream states until the time when participating is an expert. This usually requires that the PC recognizes a vast number of specifications and can take several hours or several days.

Post processing: The last step following the results from the solver is to analyze the results using different technique, such as weight and speed shape tracks, vector track, streamlines, temperature type, etc. after a model is grasped. Post planning is either in 2-D or 3-D simple representations.

\section{ANALYSIS OF HEAT EXCHANGER}

Shell and tube heat exchangers consist of a series of tubes. One set of these tubes contains the fluid that must be either heated or cooled. The second fluid runs over the tubes that are being heated or cooled so that it can either provide the heat or absorb the heat required. A software model is proficient by utilizing amounts of shell and tubes designs in ANSYS 14.0, Workbench structure modeler is utilized to develop Heat exchanger geometry and for further investigation. Geometry is made simple by offering a leeway for the plane symmetry. This heat exchanger is counter flow type and the tube side consists of one inlet and one outlet representing three types of design of tubes in heat exchanger. After model is designed, run thermal simulation of heat exchanger. The consequences overcome were discreetly studied with general condition. Figures show the three type of variations of tubes design in heat exchanger model in Ansys CFD.

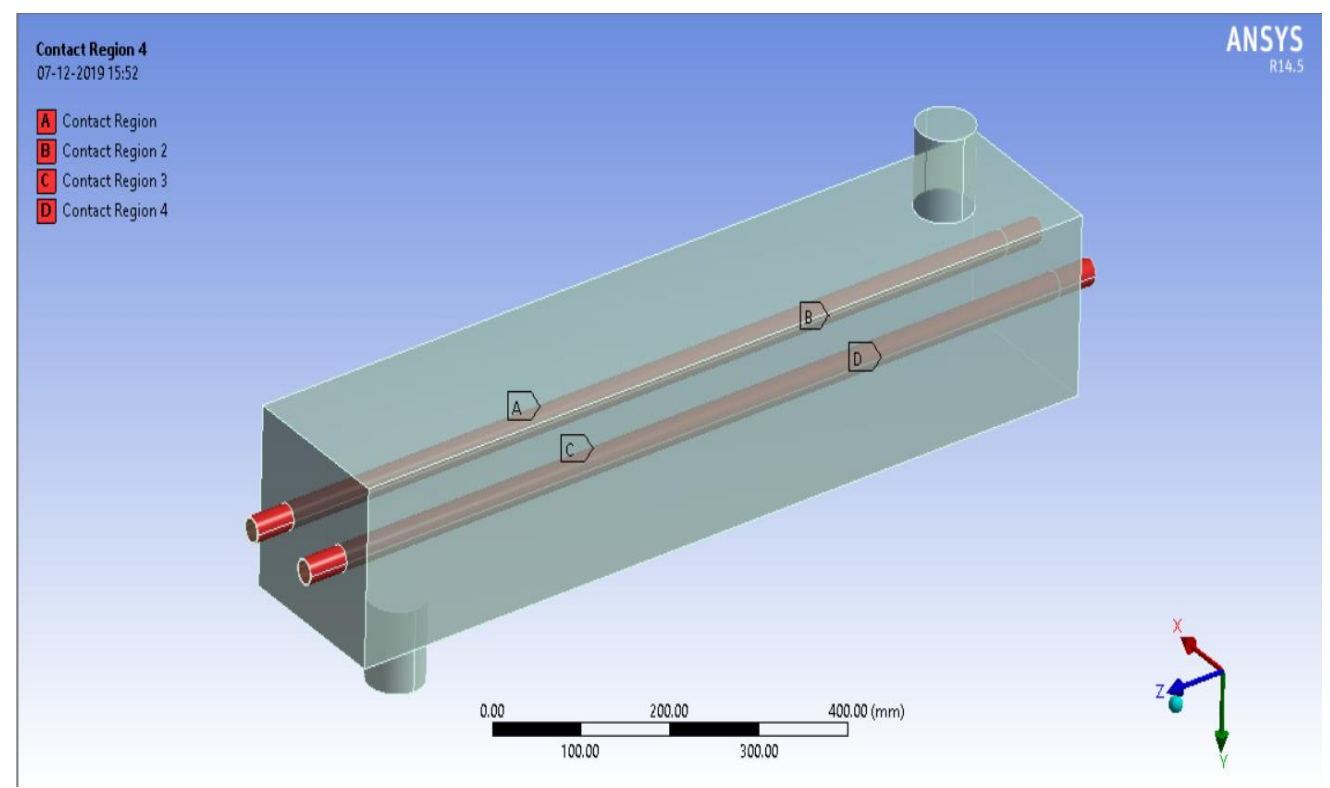

Figure 2: Parallel pipe flow tube heat exchanger 


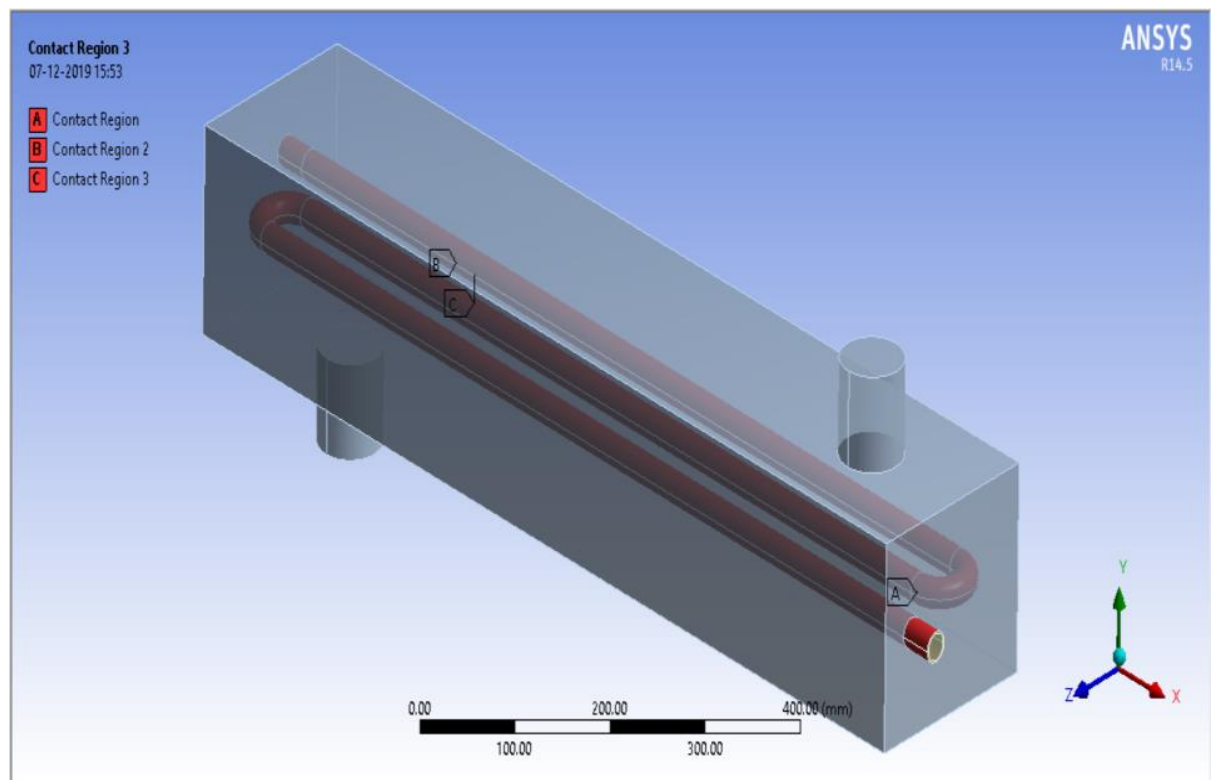

Figure 3: S Pattern pipe flow tube heat exchanger

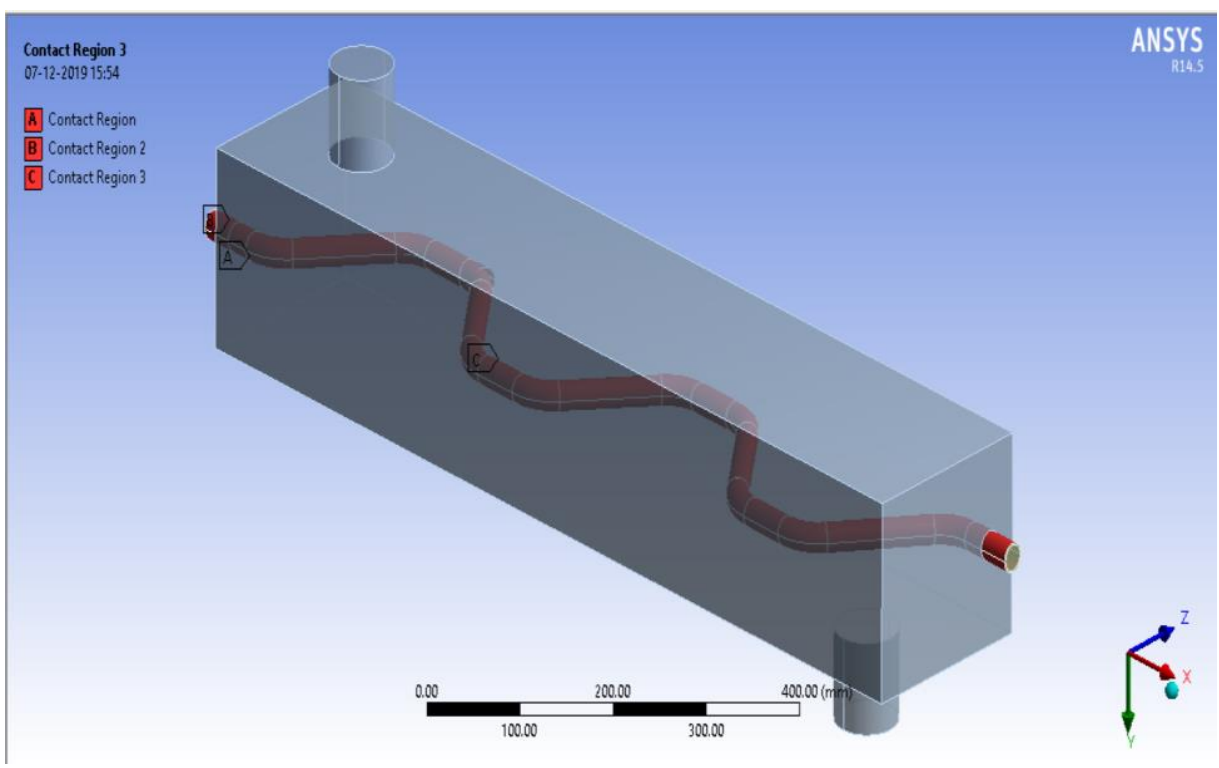

Figure 4: Zigzag pipe flow tube heat exchanger

\section{BOUNDARY CONDITIONS}

Limit conditions are characterized: Inlet - Velocity delta

Inlet Outlet - weight outlet (zero-gauge Pressure)

Dividers - convective heat exchange, no slip criteria.

Liquid Material - Water and Water vapor

metal Material - copper and Steel

Energy condition - ON

Turbulence Model - K-epsilon, feasible, Standard wall treatment demonstrate

Solution Method - Second Order 


\section{RESULTS AND DISCUSSIONS}

As per CFD analysis of all three models of heat exchangers with the variations in tubes we found the inlet outlet temperatures.

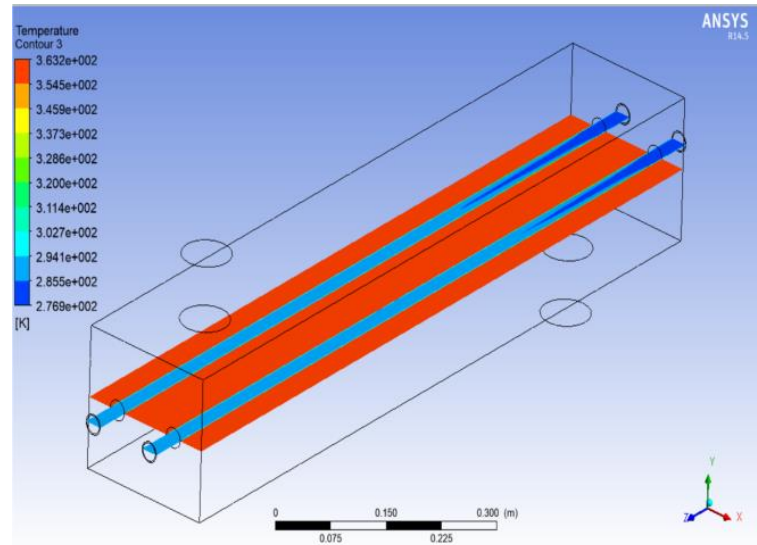

Figure 5: Parallel pipe flow temperature

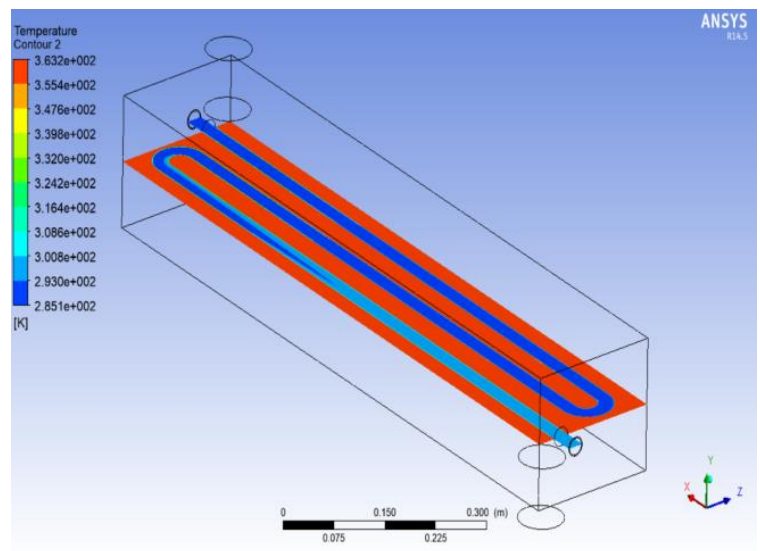

Figure 7: S Pattern pipe flow temperature

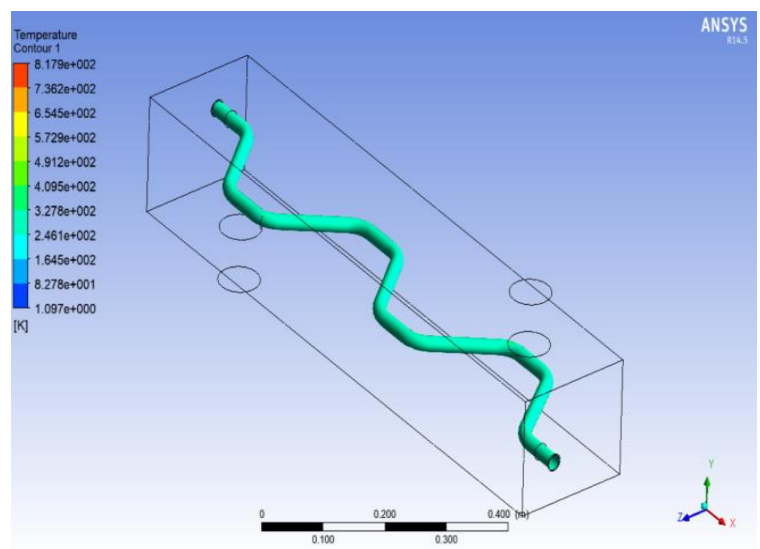

Figure 7: Zigzag Pipe flow temperature

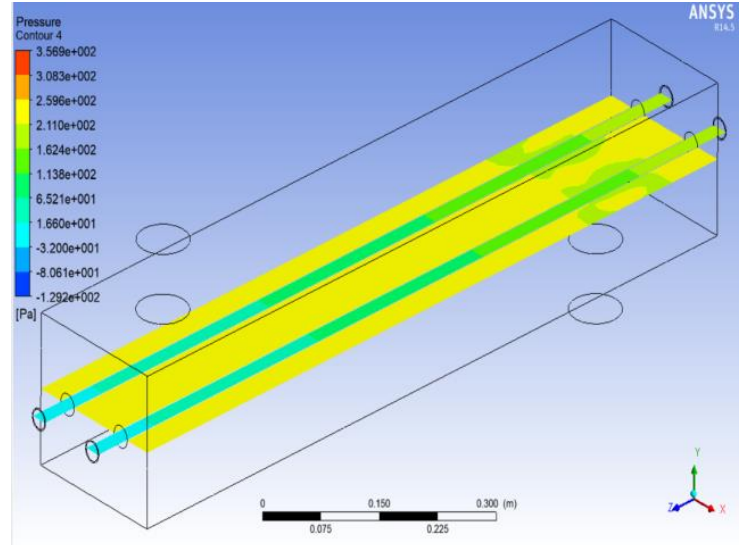

Figure 6: velocity in parallel pipe flow

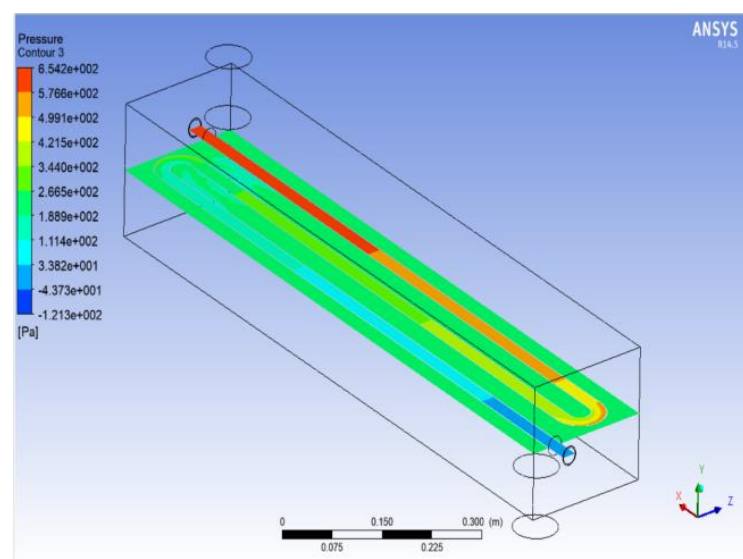

Figure 8: velocity in S Pattern pipe flow

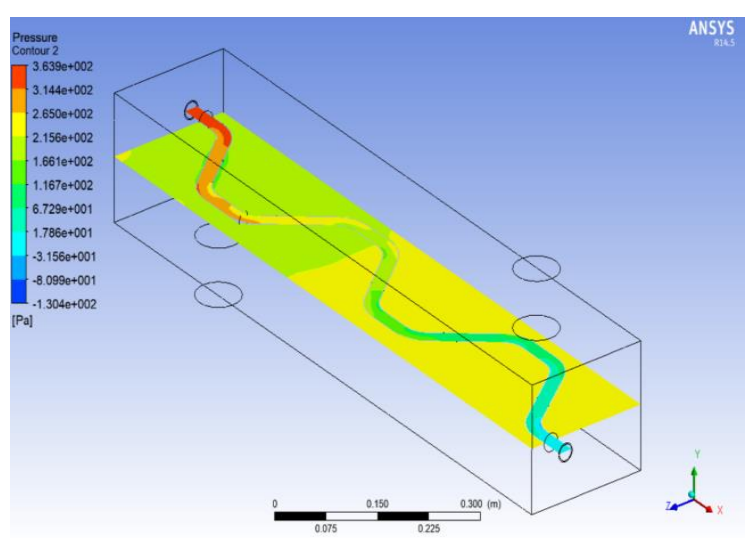

Figure 9: velocity in Zigzag Pattern pipe flow

As per study figure shows the variations of temperature difference. In above study three types of heat exchangers designed by using Ansys. Different types of tube used in heat exchanger i.e. Parallel flow tubes, 'S' pattern tubes, and Zigzag flow pattern tubes. After designing cold water inlet temperature given $12^{\circ} \mathrm{C}$ and hot water temperature given at inlet is $90^{\circ} \mathrm{C}$. as per CFD analysis heat exchange in designed exchanger and results optimized. 
CFD Analysis of Heat Exchanger Models Design Using Ansys Fluent

Table 1: Cold water flow temperatures at inlet and outlet

\begin{tabular}{|l|c|c|}
\hline \multicolumn{1}{|c|}{ Pattern of Tubes } & Cold inlet $\left({ }^{\circ} \mathbf{C}\right)$ & Cold outlet $\left({ }^{\circ} \mathbf{C}\right)$ \\
\hline Parallel tubes & 12 & 21 \\
\hline 'S' Pattern tubes & 12 & 35 \\
\hline Zigzag Pattern tubes & 12 & 54 \\
\hline
\end{tabular}

Table 2: Hot water Temperatures at inlet and outlet

\begin{tabular}{|l|c|c|}
\hline \multicolumn{1}{|c|}{ Pattern of Tubes } & Hot inlet $\left({ }^{\circ} \mathbf{C}\right)$ & Hot outlet $\left({ }^{\circ} \mathbf{C}\right)$ \\
\hline Parallel tubes & 90 & 81 \\
\hline 'S' pattern tubes & 90 & 80 \\
\hline Zigzag Pattern tubes & 90 & 70 \\
\hline
\end{tabular}

Table 3: Pressure and velocity at outlets

\begin{tabular}{|l|c|c|}
\hline \multicolumn{1}{|c|}{ Results } & Max Pressure (Pa) & Max Velocity (m/s) \\
\hline Straight tubes & 3.56 & 6.87 \\
\hline S Pattern tubes & 6.54 & 6.88 \\
\hline Zigzag Pattern Tubes & 3.63 & 6.68 \\
\hline
\end{tabular}

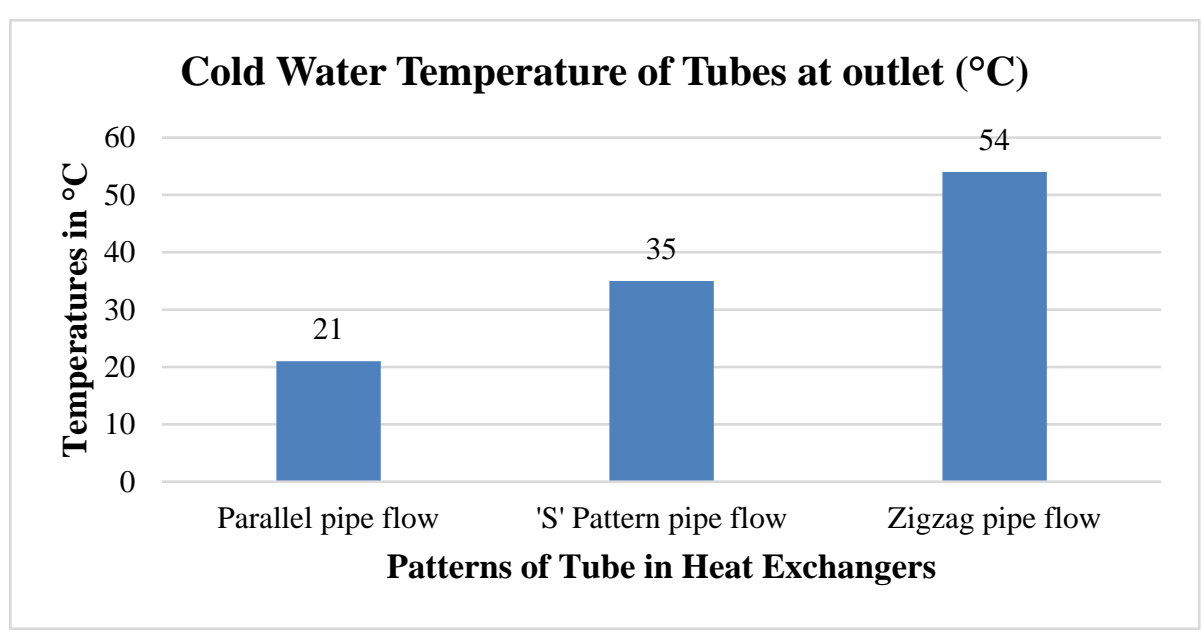

Figure 10: Cold water temperatures with Patterns of Tube in Heat Exchangers

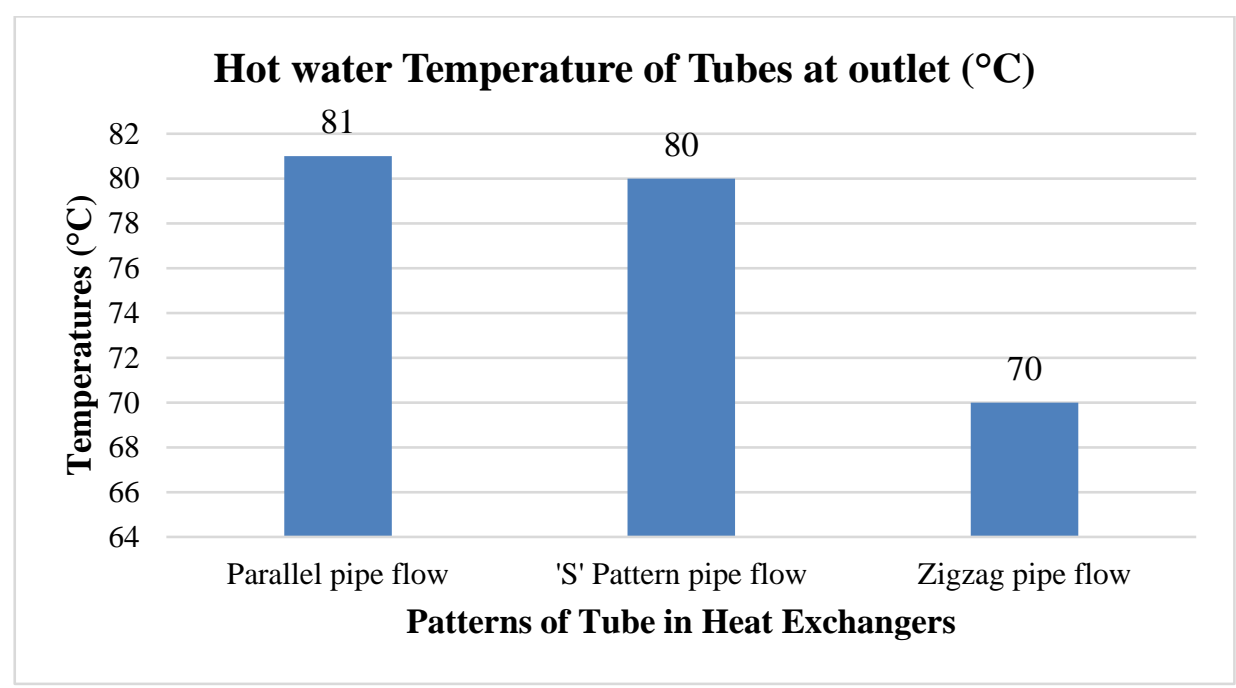

Figure 11: Hot water temperatures with Patterns of Tube in Heat Exchangers 


\section{CONCLUSION}

From this study we select Copper material to the tubes and steel material to shell design then studied in Ansys and optimized the best possible value of temperature variations amongst the discussed materials. so that it may be assumed that no heat transfer is taking place in between shell and surroundings. As per results it is concluded that Zigzag pattern tube design gives better heat transfer in heat exchanger as comparison to others.

- Cold water during Parallel flow tubes give $21^{\circ} \mathrm{C}$ temp at outlet which is decreases from $12^{\circ} \mathrm{C}$.

- $\quad$ 'S' pattern tubes give $35^{\circ} \mathrm{C}$ temperature at outlet during cold water flow and Zigzag tube pattern gives $54^{\circ} \mathrm{C}$ temperature of cold-water flow at outlet.

- Hot water during Parallel flow tubes give $81^{\circ} \mathrm{C}$ temp at outlet which is decreases from $90^{\circ} \mathrm{C}$.

- In hot water flow 'S' pattern tubes give $80^{\circ} \mathrm{C}$ temperature at outlet during hot water flow and Zigzag tube pattern gives $70^{\circ} \mathrm{C}$ temperature of hot-water flow at outlet.

- So, after comparing these results we found the maximum heat transfer at Zigzag pattern of heat exchanger. So Zigzag pattern design is optimum design for maximum heat transfer.

\section{REFERENCES}

[1] M.D. Rajkamal, M. Mani Bharathi, Shams Hari Prasad, "Thermal Analysis of Shell and Tube Heat Exchanger", International Journal of Pure and Applied Mathematics, Volume 119 No. 12 2018, 14299-14306.

[2] Shuvam Mohanty, Shofique Uddin Ahmed, "Performance prediction of Counter flow Heat Exchanger by using CFD technique", IJEDR, Volume 6, Issue 2, ISSN: 2321-9939.

[3] Ankush S. Patil, H. S. Farkade, "Advances in Design and Development of Heat Exchangers: A Review", International Research Journal of Engineering and Technology (IRJET), Volume: 04, Issue: 05, May -2017.

[4] Chandan Kumar Sethi, "CFD Analysis on Effectiveness of a Plate Type Heat Exchanger Using Sea Water and Engine Oil", International Journal of Advanced Mechanical Engineering, Volume 12, Number 1 (2017) pp. 191-198.

[5] Deepa Shrivastava, Rahul Mishra, "Cfd Analysis of Heat Transfer for Tube-In- Tube Heat Exchanger", International Journal of Recent Trends in Engineering \& Research (IJRTER), Volume 03, Issue 08, August - 2017.

[6] Dipankar De, Tarun K. Pal, Santanu Bandyopadhyay, "Helical baffle design in shell and tube type heat exchanger with CFD analysis", International Journal of Heat and Technology, Vol. 35, No. 2, June 2017, pp. 378-383.

[7] Kvenumadhav, Sudhanshu Kumar, Chandrashekar Goud, "Performance Analysis of Different Heat Exchanger Design Using Cfd Simulation", IJRAET, Volume 6, Issue 2 OCT 2017.

[8] Mohammed Irshad, Mohammed Kaushar, G. Rajmohan, "Design and CFD Analysis of Shell and Tube Heat Exchanger", IJESC, Volume 7 Issue No.4, 2017.

[9] Q. Miao, Z. Wang, L. Wang, "A Failure Analysis of Air Heat Exchanger Based on Modal Calculation and Thermal-Structural Interaction Simulation", International Journal of Materials, Mechanics and Manufacturing, Vol. 5, No. 3, August 2017.

[10] Basawaraj S. Hasu, J. Govardhan, Satyanarayana Rao, "Thermal Analysis of Tubular Heat Exchangers Using Ansys By Using Alloy Materials as Tube Materials", Anveshana's International Journal of Research in Engineering and Applied Sciences, Volume 1, Issue 3, 2016. 
[11] K Ashok Reddy, "A Review of Heat Transfer Studies for Shell \& Tube Heat Exchangers", IJSDR, Volume 1, Issue 5, May 2016.

[12] J. BalaBhaskara Rao, V. Ramachandra Raju, "Numerical and heat transfer analysis of shell and tube heat exchanger with circular and elliptical tubes", Rao and Raju International Journal of Mechanical and Materials Engineering Volume 11, Issue 6, DOI 10.1186/s40712-016-0059-x.

[13] Mayank Bhola, Vinod Kumar, Satyendra Singh, "Heat Transfer Enhancement in Concentric Tube Heat Exchanger in ANSYS FLUENT", International Journal of Engineering Research \& Technology (IJERT), Vol. 4 Issue 04, April-2015.

[14] Pankaj D. Lad, Santosh G. Taji, Baban B. Londhe, "Optimization of Concentric Pipe Heat Exchanger as Per Asme Code using Finite Element Analysis", International Journal on Recent Technologies in Mechanical and Electrical Engineering (IJRMEE), Volume: 2 Issue: 10, ISSN: 2349-7947, 2015.

[15] Roshan. V. Marode, Ashok. J.Keche, "Thermal Analysis Validation for Different Design Tubes in a Heat Exchanger", International Journal of Engineering Research and General Science Volume 3, Issue 1, January-February, 2015. 